・生态保护红线专题・

\title{
中国生态环境脆弱区范围界定
}

\author{
刘军会 ${ }^{1}$ 邹长新 ${ }^{*}$ 高吉喜 $^{2}$ 马 苏 $^{1}$ 王文杰 $^{1}$ 吴 坤 $^{3}$ 刘 洋 ${ }^{1}$ \\ 1 (中国环境科学研究院, 北京 100012) \\ 2 (环境保护部南京环境科学研究所, 南京 210042) \\ 3 (茂名市环境保护监测站, 广东茂名 525000)
}

\begin{abstract}
摘要: 中国生态环境脆弱区既是生态退化区域，也是贫困人口集中分布区，但其空间分布范围至今仍然不明确。 本研究针对土地沙化、水土流失和石漠化等典型生态问题, 采用遥感和GIS技术, 建立评价指标体系及评价模型, 综合评价了全国生态环境敏感性, 定量揭示敏感性空间分布特征。在此基础上, 结合政府文件和已有的研究成果, 识别出全国生态脆弱区分布范围。结果显示, 生态极敏感区主要分布在我国西北干旱/半干旱地区、西南湿润地区、 东南湿润地区以及黄土高原丘陵沟壑区; 高度敏感区主要分布在阿尔泰山、天山、阴山南麓、科尔沁沙地、呼伦 贝尔沙地、㒸塘高原西部、横断山和东南丘陵山地等区域。在全国划定了 18 个重点生态脆弱区, 总面积 240.1 万 $\mathrm{km}^{2}$, 并明确了每个脆弱区的名称、类型、面积、分布范围以及面临的主要生态问题。完成的中国生态脆弱区分布图为 全国生态保护红线划定提供了参考底图。
\end{abstract}

关键词: 生态脆弱区, 综合生态敏感性, 遥感, GIS, 空间边界

\section{Location determination of ecologically vulnerable regions in China}

\author{
Junhui Liu ${ }^{1}$, Changxin Zou ${ }^{2 *}$, Jixi Gao ${ }^{2}, \mathrm{Su} \mathrm{Ma}^{1}$, Wenjie Wang ${ }^{1}, \mathrm{Kun} \mathrm{Wu}^{3}$, Yang Liu ${ }^{1}$ \\ 1 Chinese Research Academy of Environmental Sciences, Beijing 100012 \\ 2 Nanjing Institute of Environmental Sciences, Ministry of Environmental Protection, Nanjing 210042 \\ 3 Maoming Municipal Environmental Protection Monitoring Station, Maoming, Guangdong 525000
}

\begin{abstract}
Ecologically vulnerable regions in China are not only the most serious areas of environmental degradation, but also the most poverty-stricken regions. However, these regions are still undefined. Three typical factors including land desertification, soil erosion and rocky desertification were selected to establish an evaluation model of eco-environmental sensitivity by using Remote Sensing (RS) and Geographic Information System (GIS) technology. We conducted a comprehensive research on eco-environmental sensitivity to reveal its spatial features in a quantitative way in China, and redefine the location of ecologically vulnerable regions integrated with the existing relevant government documents and the previous research. Results are demonstrated as follows: the extremely sensitive areas are distributed in northwestern, southwestern, southeastern parts of China and loess hilly regions; the highly sensitive areas are located in the Altai Mountains, the Tianshan Mountains, the southern part of Yinshan Mountains, the Horqin Sandy Land, the Hulun Buir Sandy Land, the western part of Chang Tang Plateau, the Hengduan Mountains and the hilly mountains regions in Southeast China. A total of 18 ecological vulnerable regions in China were defined, comprising a total area of 2.4 million $\mathrm{km}^{2}$. The name, type, area, spatial distribution and the main ecological problems of each region were characterized. The spatial distribution map of ecologically vulnerable regions in China can be used as a base map for the redline delimitation of national ecological protection.
\end{abstract}

Key words: ecologically vulnerable regions, comprehensive ecological sensitivity, RS, GIS, range

为保障国家和区域生态安全，《中华人民共和 国环境保护法》规定，国家在重点生态功能区、生
态环境敏感区和脆弱区等区域划定生态保护红线, 实行严格保护。可见, 划定生态保护红线首先要明

收稿日期: 2015-06-01; 接受日期: 2015-08-17

基金项目: 国家环境保护公益性行业科研专项(201209027)和国家自然科学基金(41471092)

* 通讯作者 Author for correspondence. E-mail: zcx@nies.org 
确重点生态功能区、生态环境敏感区和脆弱区等的 空间分布范围。国务院2011年印发的《全国主体功 能区规划》确定了 25 个重点生态功能区, 总面积约 386 万 $\mathrm{km}^{2}$, 占全国陆地国土面积的 $40.2 \%$ 。2008年 环境保护部和中国科学院共同编制完成的《全国生 态功能区划》以水源涵养、土壤保持、防风固沙、 生物多样性保护和洪水调蓄5类主导生态调节功能 为基础, 确定了 50 个重要生态服务功能区域。25个 重点生态功能区和50个重要生态服务功能区域均 具有明确边界, 为全国生态保护红线划定奠定了基 础。生态脆弱区指生态系统组成结构稳定性较差, 抵抗外在干扰和维持自身稳定的能力较弱, 易于发 生生态退化且难以自我修复的区域。我国生态脆弱 区类型多、范围广 (田亚平和常昊, 2012), 已有研究 主要以西南喀斯特地区、北方农牧交错带、西北干 旱地区、南方丘陵山区和青藏高寒区等典型区域为 主(苏维词和杨汉奎, 1994; 罗承平和薛纪瑜, 1995; 王让会等, 2001; 兰安军等, 2003; 于伯华和吕昌河, 2011), 在全国尺度上开展的生态脆弱区研究相对 缺乏, 国家相关部门也未发布边界清晰的全国生态 脆弱区分布图, 这成为全国生态保护红线划定亟待 解决的关键问题。

20 世纪 60 年代以来, 国际生物学计划(IBP)、人 与生物圈计划( MAB) 以及地圈-生物圈计划(IGBP) 均将生态环境脆弱区作为重要研究对象。20世纪 80 年代, 国内开始出现生态环境脆弱区的基础判定研 究(牛文元, 1989)。赵跃龙和刘燕华(1994)按照脆弱 生态环境的主要成因, 绘制了北方半干旱-半湿润 区、西北干旱区、华北平原区、南方丘陵地区、西 南山地区、西南石灰岩山地区以及青藏高原区七大 类脆弱生态环境类型分布图。由于近几十年全球气 候变化的影响, 年降水量、地下水位、植被覆盖度 等评价指标不断发生变化, 脆弱生态环境分布范围 也相应发生了一定程度的变化。环境保护部2008年 印发的《全国生态脆弱区保护规划纲要》以生态交 错带为主体, 确定了 8 个生态脆弱区: 东北林草交 错生态脆弱区、北方农牧交错生态脆弱区、西北荒 漠绿洲交接生态脆弱区、南方红壤丘陵山地生态脆 弱区、西南岩溶山地石漠化生态脆弱区、西南山地 农牧交错生态脆弱区、青藏高原复合侵蚀生态脆弱 区、沿海水陆交接带生态脆弱区, 但未发布全国生 态脆弱区空间分布图。《全国主体功能区规划》指
出, 我国中度以上生态脆弱区域占全国陆地国土面 积的 $55 \%$, 其中极度脆弱区域占 $9.7 \%$, 重度脆弱区 域占 $19.8 \%$ ，中度脆弱区域占 $25.5 \%$ 。脆弱的生态环 境使大规模高强度的工业化城镇化开发只能在有 限区域集中展开。发布的全国生态脆弱性评价图, 即是依据沙漠化、水土流失、石漠化分布图，以公 里格网为单元, 经单要素及综合的生态敏感性评估 绘制而成。

崔胜辉等(2009)研究认为, 敏感性评价与脆弱 性评价关系紧密, 在研究包含人类社会的复合系统 的脆弱性时, 需要从暴露分析、敏感性评价和适应 能力评价 3 个方面进行; 当单独针对自然生态系统 时, 因为其在应对全球环境快速变化时缺乏主动适 应和调节能力, 分区敏感程度也就是脆弱程度。因 此, 针对自然生态系统开展的生态敏感性和脆弱性 评价, 二者空间重叠比例高, 面临的生态问题(土地 沙化、水土流失、石漠化等)大体相同, 在此情况下 可通过开展生态敏感性评价识别出生态脆弱区。

为此, 本研究针对土地沙化、水土流失和石漠 化等典型生态问题，采用遥感和GIS技术，建立评 价指标体系和评价模型，开展全国生态敏感性综合 评价, 定量揭示生态敏感性程度和地域差异。在此 基础上，结合政府文件和已有研究成果，划定全国 生态脆弱区的空间范围, 以期为全国生态保护红线 划定提供底图和技术支撑。

\section{1 方法}

\section{1 数据收集与处理}

(1)遥感数据：覆盖全国的2000-2010年归一化 植被指数(Normalized Difference Vegetation Index, NDVI) 来源于美国国家航空航天局 (NASA) 的 EOS/MODIS 数据产品 (http://e4ft101.cr.usgs.gov/), 空间分辨率为 $250 \mathrm{~m}$, 时间分辨率为 $16 \mathrm{~d}$ 。为消除异 常值的影响, 采用最大合成法 (maximum value composites, MVC)合成月NDVI数据, 再将月NDVI 合成年最大NDVI影像(刘宪锋等, 2013), 获取全国 2000-2010年逐年及逐月NDVI影像。

(2)气象数据: 全国2000-2010年降雨量、温度、 风速和大风日数资料来源于中国气象科学数据共 享服务网中的中国地面气候资料数据集(http://cdc. cma.gov.cn/)。数据内容包括全国各气象站点的编 号、经纬度和海拔，以及每个气象站点在相应分析 
时间尺度内的降雨量 $(0.1 \mathrm{~mm})$ 、温度 $\left(0.1^{\circ} \mathrm{C}\right)$ 、风速 $(0.1 \mathrm{~m} / \mathrm{s})$ 。根据各气象站点的经纬度信息, 采用 ArcGIS的Kriging空间插值法, 获取全国气象数据 栅格图像。

(3)高程数据: 基于 $1: 25$ 万数字高程模型(DEM) 提取坡度等地形数据。

(4)土壤数据: 土壤数据来源于中国科学院南 京土壤研究所的中国 $1: 100$ 万土壤数据库。属性数据 库包括土壤表层粘粒、粉沙、沙粒、有机质含量等 属性字段。

(5)其他数据: 1:50万地质岩性图, 用于提取岩 溶分布地区。

本研究中所用数据均统一转换成阿尔伯斯等 面积圆雉投影(Albers conical equal area projection), 采用克拉索夫斯基(Krasovsky)椭球体, 栅格单元为 $250 \mathrm{~m} \times 250 \mathrm{~m}$ 。

\section{2 生态敏感性评价方法}

\subsection{1 指标体系}

生态敏感性评价主要包括土地沙化、水土流 失、石漠化敏感性评价, 其他类型生态敏感性评价 方法可参考原国家环境保护总局 2003 年发布的《生 态功能区划技术暂行规程》 (http://sts.mep.gov. cn/stbh/stglq/200308/t2003-0815_90755.htm/)。

(1)指标选取。基于区域自然生态环境现状及演
变特征, 参照《生态功能区划技术暂行规程》, 构 建生态敏感性评价指标体系(表1)。土地沙化主要受 气候干燥程度影响, 表现为气候干燥, 植物生长困 难, 地表植被覆盖度低。干燥气候减缓了地表土壤 形成过程，使地表结构分散，易受风蚀，土壤的抗 风蚀沙漠化能力与土壤水分含量成正比(欧阳志云 等, 2000; 王小丹等, 2004)。根据刘连友等(1998)研 究结果, 砂质壤土、壤质砂土和固定风砂土的起动 风速分别为 $6.0 、 6.6$ 和 $5.1 \mathrm{~m} / \mathrm{s}$, 本研究采用冬春季节 $\geqslant 6 \mathrm{~m} / \mathrm{s}$ 起沙风天数。因此, 选取干燥度指数、 $\geqslant 6$ $\mathrm{m} / \mathrm{s}$ 起沙风天数、土壤质地、植被覆盖度作为土地 沙化敏感性评价指标。水土流失敏感性评价根据通 用水土流失方程基本原理，选择降雨侵蚀力、土壤 可蚀性、坡度以及植被覆盖度作为评价指标。石漠 化是指在热带、亚热带湿润地区岩溶及其发育的自 然背景下, 由于人类活动的干扰，地表植被遭受破 坏, 造成土壤严重侵蚀, 基岩大面积裸露, 砾石堆 积, 地表呈现似荒漠化景观的土地退化乃至消失的 现象(张殿发等, 2002; 肖荣波等, 2005)。根据石漠 化形成机理, 选取碳酸盐出露面积百分比、坡度和 植被覆盖度构建石漠化敏感性评价指标体系。

(2)指标计算。干燥度指数采用修正的谢良尼诺 夫公式(中国科学院自然区划工作委员会，1959)计 算。采用GIS空间插值获取全国起沙风分布图(潘峰

表1 生态环境敏感性评价指标及分级赋值

Table 1 Evaluation indices and classification of ecological environmental sensitivity

\begin{tabular}{|c|c|c|c|c|c|c|}
\hline & 指标 Index & $\begin{array}{c}\text { 不敏感 } \\
\text { Insensitive }\end{array}$ & $\begin{array}{l}\text { 轻度敏感 } \\
\text { Lightly } \\
\text { sensitive } \\
\end{array}$ & $\begin{array}{c}\text { 中度敏感 } \\
\text { Moderate sensitive }\end{array}$ & $\begin{array}{c}\text { 高度敏感 } \\
\text { Highly sensitive }\end{array}$ & $\begin{array}{c}\text { 极敏感 } \\
\text { Extremely sensitive }\end{array}$ \\
\hline \multirow{4}{*}{$\begin{array}{l}\text { 土地沙化 } \\
\text { Land } \\
\text { desertification }\end{array}$} & 干燥度指数 Aridity index & $\leqslant 1.0$ & $1.0-1.5$ & $1.5-4.0$ & $4.0-16.0$ & $\geqslant 16.0$ \\
\hline & $\begin{array}{l}\geqslant 6 \mathrm{~m} / \mathrm{s} \text { 起沙风天数 } \\
\text { Days with wind speed } \geqslant 6 \mathrm{~m} / \mathrm{s} \mathrm{(d)}\end{array}$ & $\leqslant 5$ & $5-10$ & $10-20$ & $20-30$ & $\geqslant 30$ \\
\hline & 土壤质地 Soil texture & 基岩 Bedrock & 粘质 Clay & 砾质 Gravel & 壤质 Loam & 砂质 Sandy \\
\hline & $\begin{array}{l}\text { 植被覆盖度 } \\
\text { Vegetation coverage (\%) }\end{array}$ & $\geqslant 80$ & $60-80$ & $40-60$ & $20-40$ & $\leqslant 20$ \\
\hline \multirow{4}{*}{$\begin{array}{l}\text { 水土流失 } \\
\text { Soil erosion }\end{array}$} & 降雨侵蚀力 Rainfall erosivity & $<25$ & $25-100$ & $100-400$ & $400-600$ & $>600$ \\
\hline & 土壤可蚀性 Soil erodibility & $<0.27$ & $0.27-0.42$ & $0.42-0.52$ & $0.52-0.62$ & $>0.62$ \\
\hline & 坡度 Slope $\left(^{\circ}\right)$ & $0-8$ & $8-15$ & $15-25$ & $25-35$ & $>35$ \\
\hline & $\begin{array}{l}\text { 植被覆盖度 } \\
\text { Vegetation coverage (\%) }\end{array}$ & $\geqslant 80$ & $60-80$ & $40-60$ & $20-40$ & $\leqslant 20$ \\
\hline \multirow[t]{3}{*}{$\begin{array}{l}\text { 石漠化 } \\
\text { Rocky } \\
\text { desertification }\end{array}$} & $\begin{array}{l}\text { 碳酸盐出露面积百分比 } \\
\text { Rate of carbonate rock outcropping areas } \\
(\%)\end{array}$ & $\leqslant 10$ & $10-30$ & $30-50$ & $50-70$ & $\geqslant 70$ \\
\hline & 坡度 Slope $\left(^{\circ}\right)$ & $\leqslant 5$ & $5-8$ & $8-15$ & $15-25$ & $\geqslant 25$ \\
\hline & $\begin{array}{l}\text { 植被覆盖度 } \\
\text { Vegetation coverage (\%) }\end{array}$ & $\geqslant 80$ & $60-80$ & $40-60$ & $20-40$ & $\leqslant 20$ \\
\hline 赋值 Grade & & 1 & 3 & 5 & 7 & 9 \\
\hline
\end{tabular}


等, 2011)。土壤质地通过 1:100万土壤数据库获取。 降雨侵蚀力分布图根据王万忠和焦菊英(1996)利用 降水资料计算的中国 100 多个城市的降雨侵蚀力值, 采用内插法绘制。土壤可蚀性采用土壤侵蚀和生产 力影响估算模型(erosion-productivity impact calculator, EPIC) (Williams et al., 1983; 史东梅等, 2012) 计算。坡度来源于SRTM (航天飞机雷达地形测绘任 务, Shuttle Radar Topography Mission) $90 \mathrm{~m}$ 分辨率 DEM数据, 通过GIS技术提取并分级。碳酸盐出露 面积百分比由区域单元范围内碳酸盐出露面积占 单元总面积的百分比计算。植被覆盖度信息是在对 光谱信号进行分析的基础上, 通过建立归一化植被 指数与植被覆盖度的转换关系直接提取(Pan et al., 2005)。

(3)指标分级。ArcGIS提供了定义间隔(defined interval)、等距(equal interval)、等量(quantile)、标准 差(standard deviation)、自然断点(natural breaks)等常 用分类方法。其中, 自然断点分类方法是利用统计 学的Jenk最优化法得出分界点, 以使各级的内部方 差之和最小(肖荣波等, 2005)。因此, 本研究采用自 然断点分类方法与专家知识结合确定评价指标分 级赋值标准, 并将指标划分为不敏感、轻度敏感、 中度敏感、高度敏感和极敏感5级(表1)。

\subsection{2 评价模型}

生态敏感性综合评价涉及诸多评价因子, 任何 因子受影响程度一旦超过阈值, 整体生态系统将受 到严重破坏。为突出生态环境问题的敏感性, 在对 多个生态环境因子进行综合评价时, 采取极大值 法, 即取各因子敏感性评价结果中的最大值进行综 合评价(潘峰等, 2011):

$$
\begin{aligned}
& I=\max \left(D_{\mathrm{i}}, S_{\mathrm{i}}, R_{\mathrm{i}}\right) \\
& D_{\mathrm{i}}=\sqrt[4]{A_{\mathrm{i}} \times W_{\mathrm{i}} \times K_{\mathrm{i}} \times C_{\mathrm{i}}}
\end{aligned}
$$

$$
\begin{aligned}
& S_{\mathrm{i}}=\sqrt[4]{F_{\mathrm{i}} \times E_{\mathrm{i}} \times T_{\mathrm{i}} \times C_{\mathrm{i}}} \\
& R_{\mathrm{i}}=\sqrt[3]{M_{\mathrm{i}} \times T_{\mathrm{i}} \times C_{\mathrm{i}}}
\end{aligned}
$$

式中, $I$ 为生态敏感性综合评价结果, $D_{\mathrm{i}}$ 为 $i$ 评价单元 土地沙化敏感性指数; $S_{\mathrm{i}}$ 为 $i$ 评价单元水土流失敏感 性指数; $R_{\mathrm{i}}$ 为 $i$ 评价单元石漠化敏感性指数; $A_{\mathrm{i}} 、 W_{\mathrm{i}}$, $K_{\mathrm{i}} 、 C_{\mathrm{i}} 、 F_{\mathrm{i}} 、 E_{\mathrm{i}} 、 T_{\mathrm{i}} 、 M_{\mathrm{i}}$ 分别为 $i$ 平价单元的干燥度指 数、起沙风天数、土壤质地、植被覆盖度、降雨侵 蚀力、土壤可蚀性、坡度和碳酸盐出露面积百分比 敏感性等级值。

\subsection{3 分级标准}

采用自然断点分类与专家知识相结合的方法, 将生态敏感性评价结果分为 5 级, 即不敏感 $(1.0-2.0)$ 、轻度敏感(2.1-4.0)、中度敏感(4.1-6.0)、 高度敏感 $(6.1-8.0)$ 和极敏感 $(>8.0)$ 。

\section{3 空间分布范围确定方法}

依据生态敏感性综合评价分级结果, 结合《全 国主体功能区规划》、《全国生态脆弱区保护规划纲 要》关于生态脆弱区的描述、水利部2006年发布的 《关于划分国家级水土流失重点防治区的公告》的 42 个国家级水土流失重点防治区分布范围和已有 的研究成果, 将敏感性等级高的区域划为生态脆弱 区。划定过程中, 生态脆弱区边界确保与山脉、河 流、植被等要素自然地理边界保持一致, 以维护森 林、草地、湿地、荒漠等生态系统的完整性。

\section{2 结果}

\section{1 生态敏感性综合评价}

表2、图1显示，生态极敏感区占陆域国土面积 的 $10.4 \%$, 主要分布在北方干旱半干旱地区的沙漠 边缘和沙地、降水强度较大的西南湿润地区、东南 湿润地区以及环境异常脆弱的黄土高原丘陵沟壑

表2 生态敏感性评价等级面积比例

Table 2 Area percentage of each ecological environmental sensitivity type in China

\begin{tabular}{lcccc} 
敏感等级 & $\begin{array}{c}\text { 土地沙化敏感性 } \\
\text { Land desertification } \\
\text { Srade of sensitivity }\end{array}$ & $\begin{array}{c}\text { 水土流失敏感性 } \\
\text { Soil erosity } \\
\text { sensitivity }\end{array}$ & $\begin{array}{c}\text { 石漠化敏感性 } \\
\text { Rocky } \\
\text { desertification }\end{array}$ & $\begin{array}{c}\text { 综合生态敏感性 } \\
\text { Comprehensive ecological } \\
\text { Sensitivity }\end{array}$ \\
\hline 不敏感 Insensitive & 34.5 & 33.8 & 93.2 & 22.7 \\
轻度敏感 Lightly sensitive & 41.3 & 37.7 & 1.5 & 27.1 \\
中度敏感 Moderately sensitive & 11.7 & 13.7 & 3.4 & 22.0 \\
高度敏感 Highly sensitive & 8.3 & 9.1 & 1.6 & 17.8 \\
极敏感 Extremely sensitive & 4.3 & 5.8 & 0.4 & 10.4 \\
\hline
\end{tabular}




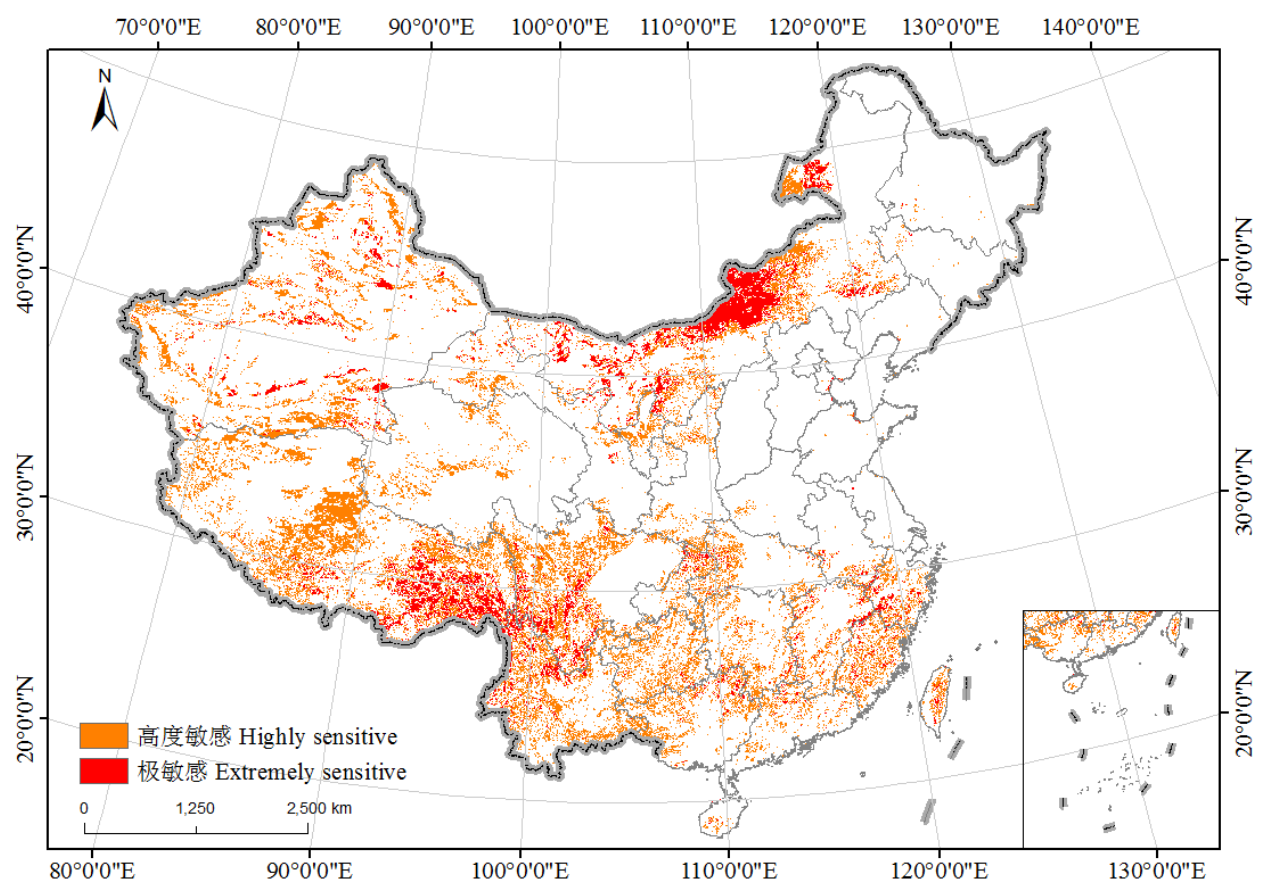

图1 全国生态环境敏感性综合评价分布图

Fig. 1 Comprehensive evaluation of ecological environmental sensitivity in China

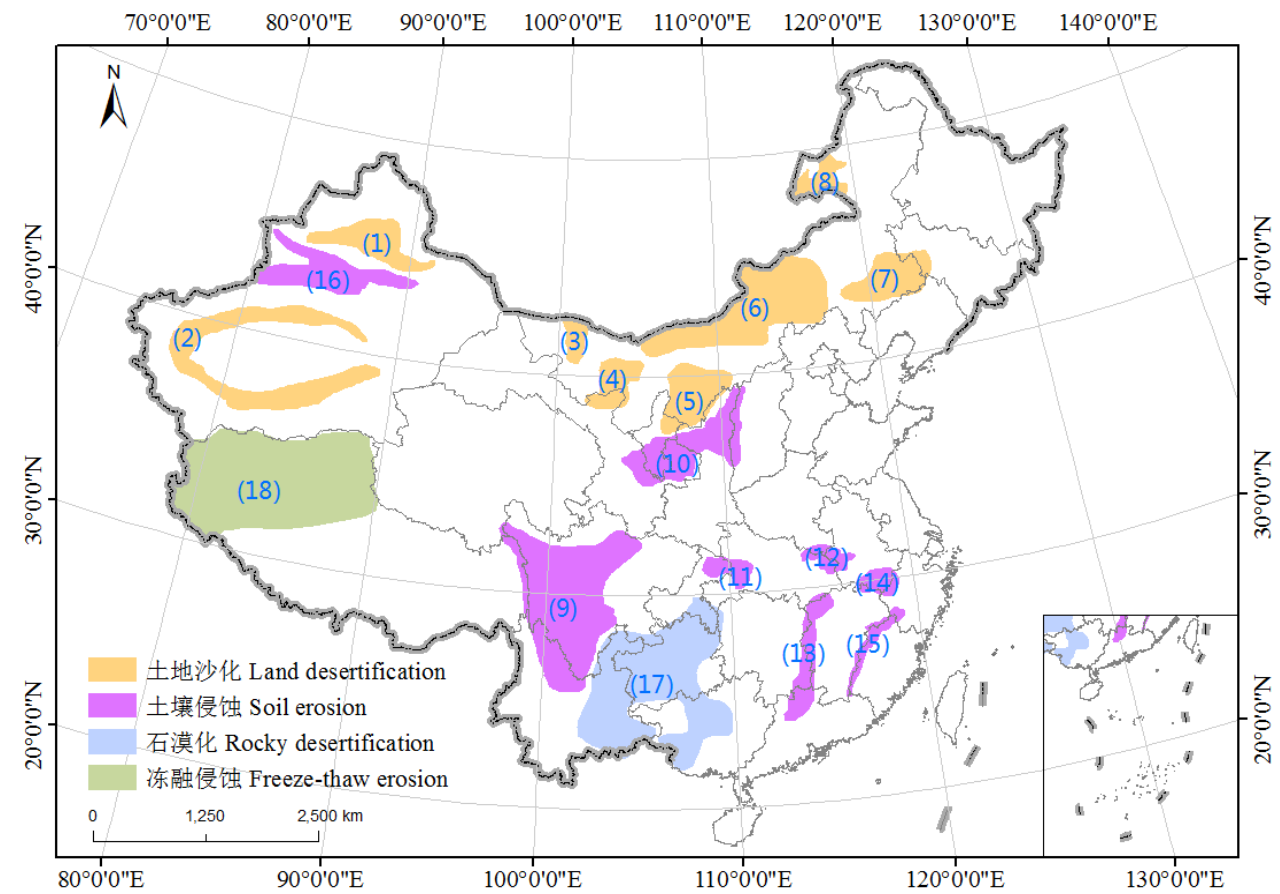

图2 中国生态环境脆弱区空间分布图。(1)古尔班通古特沙漠边缘; (2)塔克拉玛干沙漠边缘; (3)黑河流域中下游; (4)腾格里与 乌兰布和沙漠边缘; (5)毛乌素沙地; (6)阴山北麓-浑善达克沙地; (7)科尔沁沙地; (8)呼伦贝尔沙地; (9)横断山; (10)黄土高原丘 陵沟壑区; (11)三峡库区; (12)大别山; (13)罗霄山; (14)黄山; (15)仙霞岭-武夷山; (16)天山; (17)西南喀斯特地区; (18)羌塘高原 西部。

Fig. 2 Spatial distribution of ecologically vulnerable regions in China. (1) Edge of Gurbantunggut Desert; (2) Edge of Taklimakan Desert; (3) Middle and lower reaches of Heihe River; (4) Edge of Tengger Desert and Wulanbuhe Desert; (5) Mu Us Sandy Land; (6) Northern region of the Yinshan Mountains-Hunshandak Sandy Land; (7) Horqin Sandy Land; (8) Hulun Buir Sandy Land; (9) the Hengduan Mountains; (10) Loess Hilly gully region; (11) Three Gorges Reservoir area; (12) Dabie Mountain; (13) Luoxiao Mountain; (14) Huangshan Mountain; (15) Xianxialing Mountain-Wuyi Mountain; (16) the Tianshan Mountains; (17) Karst Areas in southwestern China; (18) Western part of ChangTang Plateau. 
区。高度敏感区占陆域国土面积的 $17.8 \%$, 主要分布 在阿尔泰山、天山、阴山南麓、科尔沈沙地、呼伦 贝尔沙地、㒸塘高原西部、西南山地和东南丘陵山 地等。

\section{2 生态脆弱区空间分布}

依据生态脆弱区空间分布范围确定方法, 在全 国尺度上初步划定 18 个重点生态脆弱区(图2), 总面 积 240.1 万 $\mathrm{km}^{2}$ ，占陆域国土面积的 $25.0 \%$ 。

(1)古尔班通古特沙漠边缘生态脆弱区。位于玛 纳斯河以东、乌伦古河以南的准格尔盆地四周, 面 积7.9万 $\mathrm{km}^{2}$ 。该区地处我国面积最大的固定、半固 定沙丘, 降水量少, 植被覆盖度低, 土地退化程 度高。

(2)塔克拉玛干沙漠边缘生态脆弱区。位于塔里 木盆地周边, 面积 19.7 万 $\mathrm{km}^{2}$ 。该区蒸发量远大于降 水量, 水资源利用过度, 胡杨 (Populus euphratica) 林等自然植被退化严重。

(3)黑河流域中下游生态脆弱区。莺落峡至正义 峡为中游, 正义峡以下为下游, 面积 2.3 万 $\mathrm{km}^{2}$ 。该区 气候干燥, 降水稀少, 多大风天气, 太阳辐射强烈, 易发生干热风、沙尘暴等自然灾害, 土地沙化、盐 渍化敏感性高。

(4)腾格里与乌兰布和沙漠边缘生态脆弱区。位 于贺兰山以西、长城以北、狼山以南和雅布赖山以 东区域, 面积 5.0 万 $\mathrm{km}^{2}$ 。该区干早少雨, 季风强劲, 森林、草地等自然植被覆盖度下降, 沙漠化扩张迅 速, 土地退化程度高。

(5)毛乌素沙地生态脆弱区。位于鄂尔多斯高原 与黄土高原之间的湖积冲积平原凹地, 面积 8.6 万 $\mathrm{km}^{2}$ 。该区受西北风沙侵蚀和人类过度放牧、垦殖、 矿产开发影响明显, 植被覆盖度低, 土地退化 明显。

(6)阴山北麓-浑善达克沙地生态脆弱区。位于 阴山以北, 锡林郭勒草原以南区域, 面积 23.4 万 $\mathrm{km}^{2}$ 。该区受东亚季风及其变迁影响明显, 气候干 旱, 多大风天气, 草地退化明显, 候鸟栖息、繁育地 遭到破坏。

(7)科尔沈沙地生态脆弱区。位于大兴安岭与冀 北山地之间的三角地带, 面积 8.3 万 $\mathrm{km}^{2}$ 。该区是我 国北方沙尘暴的主要沙源地, 气候干燥, 多大风天 气, 生态环境脆弱, 土壤机制不稳定, 土地退化 明显。
(8)呼伦贝尔沙地生态脆弱区。东为大兴安岭西 麓丘陵漫岗, 西对达㐘湖和克鲁伦河, 南与蒙古相 连, 北达海拉尔河, 面积 3.7 万 $\mathrm{km}^{2}$ 。该区土壤质地粗 疏, 多大风天气, 受过度放牧和矿产开发影响, 草 场沙化严重, 鼠虫害频发, 植被覆盖度下降, 土地 沙化敏感性高。

(9)西南横断山生态脆弱区。位于横断山山地, 面积 32.8 万 $\mathrm{km}^{2}$ 。该区新构造运动活跃, 岩层破碎, 谷坡陡峭，降雨集中，滑坡、泥石流分布广泛，水土 流失严重。

(10)黄土高原丘陵沟壑生态脆弱区。位于黄土 高原, 面积 13.4 万 $\mathrm{km}^{2}$ 。该区黄土堆积深厚, 土质疏 松，降雨集中，植被稀疏，坡面土壤侵蚀和沟道侵 蚀严重，侵蚀产沙容易淤积河道、水库。

(11)三峡库区生态脆弱区。位于四川盆地与长 江中下游平原的结合部, 面积 2.7 万 $\mathrm{km}^{2}$ 。该区坡度 大, 降水侵蚀力强, 陡坡耕种和土地垦殖强度大, 植被破坏明显, 地质灾害呈增加趋势, 土壤侵蚀量 加大。

(12)大别山生态脆弱区。位于大别山山地, 面积 2.5 万 $\mathrm{km}^{2}$ 。该区梅雨持久, 雷暴雨强, 多断裂结构, 坡度较陡, 原生森林严重破坏, 水土流失量大, 加 大了中下游洪涝灾害发生率。

(13)罗霄山生态脆弱区。位于罗霄山山地, 面积 6.3 万 $\mathrm{km}^{2}$ 。该区以山地丘陵为主, 土质疏松, 降雨集 中，植被退化明显，土壤侵蚀敏感性高。

(14)黄山山地生态脆弱区。位于黄山山地, 面积 2.5 万 $\mathrm{km}^{2}$ 。该区降雨量大且多暴雨, 坡度较陡, 花岗 岩和千枚岩分布广泛, 坡地土壤抗侵蚀能力差, 土 壤侵蚀明显。

(15)仙霞岭-武夷山生态脆弱区。位于仙霞岭、 武夷山山地, 面积 2.8 万 $\mathrm{km}^{2}$ 。该区降雨丰富且集中, 山高坡陡, 地表土质疏松, 植被退化, 水土流失 明显。

(16)天山生态脆弱区。位于天山山地, 面积 10.9 万 $\mathrm{km}^{2}$ 。该区受冰雪融水、降水和人类活动影响明 显, 坡度大, 植被覆盖度低, 水土流失明显。

(17)西南喀斯特生态脆弱区。位于西南石灰岩 分布区, 面积 39.6 万 $\mathrm{km}^{2}$ 。该区降雨充沛, 碳酸盐不 溶物含量低, 成土速率慢, 土壤允许流失量小, 植 被破坏严重, 石漠化显著。

(18)羌塘高原西部生态脆弱区。位于青藏高原 
西部, 面积 47.7 万 $\mathrm{km}^{2}$ 。该区冻土分布广泛, 坡度陡 峭, 土层浅薄, 森林形成和发育困难, 冻融交替频 繁, 土体涨缩显著, 地表草皮易于断裂蠕动, 块状 冻融岩土沿冻土坡面下滑滚落现象普遍。

\section{3 讨论与结论}

基于全国生态环境敏感性综合评价分级结果, 结合政府相关文件和已有研究成果, 在全国尺度上 初步划定了 18 个重点生态脆弱区, 总面积 240.1 万 $\mathrm{km}^{2}$, 占陆域国土面积的 $25.0 \%$ 。划定的生态脆弱区 虽然并未与生态敏感性综合评价结果保持完全一 致, 但考虑到国家环境监测与管理的实际需求, 其 空间布局基本符合《全国主体功能区规划》、《全国 生态脆弱区保护规划纲要》中关于生态脆弱区、《关 于划分国家级水土流失重点防治区的公告》发布的 国家级水土流失重点防治区的分布范围。

全国生态保护红线划定的首要步骤是确定划 定范围。目前, 政府有关文件和相关空间规划中未 明确全国生态脆弱区分布范围, 本研究提出的生态 脆弱区分布图可以为全国生态保护红线划定提供 参考底图。在生态脆弱区内, 极易出现生态问题的 区域是我国生态保护与修复的重点区域，也是人类 干扰禁止准入区域，应纳入生态红线控制范围。

生态敏感性评价方法主要参考2003年发布的 《生态功能区划技术暂行规程》, 并综合考虑地域 差异性和指标适用性, 对部分指标进行了调整。例 如, 本研究在土地沙化敏感性评价中, 采用修改后 的谢氏干燥度替换了湿润指数。孟猛等(2004)分析 了目前常用的 8 种干燥度指数, 认为修改后的谢氏 干燥度计算方法简单实用, 有着明确的生态学意 义, 与我国的实际情况对应性较强, 适合于中国气 候变化及其相关的干旱化、荒漠化等方面的研究。

我国生态问题突出、类型多样，除土地沙化、 水土流失和石漠化等典型生态问题外, 还存在酸 雨、土壤盐渍化等一系列问题, 生态敏感性综合评 价指标尚待补充完善, 由此界定的生态脆弱区范围 亦应与之作相应调整。

\section{参考文献}

Committee of Physical Regionalization of the Chinese Academy of Sciences (中国科学院自然区划工作委员会) (1959) Synthetic Physical Regionalization of China (Draft) (《中国 气候区划》(初稿)). Science Press, Beijing. (in Chinese)
Cui SH (崔胜辉), Li FY (李方一), Huang J (黄静), Yu YX (于 裕贤) (2009) Review of sensitivity research on the context of global change. Advances in Earth Science (地球科学进 展), 24, 1033-1041. (in Chinese with English abstract)

Lan AJ (兰安军), Zhang BP (张百平), Kang KN (熊康宁), An YL (安裕伦) (2003) Spatial pattern of the fragile karst environment in southwest Guizhou province. Geographical Research (地理研究), 22, 733-741. (in Chinese with English abstract)

Liu LY (刘连友), Wang JH (王建华), Li XY (李小雁), Liu YZ (刘玉璋), Tuo WQ (拓万权), Peng HM (彭海梅) (1998) Simulating measurement on the erosive of soil. Chinese Science Bulletin (科学通报), 43, 1663-1666. (in Chinese)

Liu XF (刘宪锋), Ren ZY (任志远), Lin ZH (林志慧), Liu YX (刘炎序), Zhang DH (张东海) (2013) The spatial-temporal changes of vegetation coverage in the Three-River Headwater region in recent 12 years. Acta Geographica Sinica (地理 学报), 68, 897-908. (in Chinese with English abstract)

Luo CP (罗承平), Xue JY (薛纪瑜) (1995) Ecologically vulnerable characteristics of the farming-pastoral zigzag zone in northern China. Journal of Arid Land Resources and Environment (干旱区资源与环境), 9, 1-7. (in Chinese with English abstract)

Meng M (孟猛), Ni J (倪健), Zhang ZG (张治国) (2004) Aridity index and its application in geo-ecological study. Acta Phytoecologica Sinica (植物生态学报), 28, 853-861. (in Chinese with English abstract)

Niu WY (牛文元) (1989) The discriminatory index with regard to the weakness, overlapness, and breadth of ecotone. Acta Ecologica Sinica (生态学报), 9, 97-105. (in Chinese with English abstract)

Ouyang ZY (欧阳志云), Wang XK (王效科), Miao H (苗鸿) (2000) China's eco-environmental sensitivity and its spatial heterogeneity. Acta Ecologica Sinica (生态学报), 20, 9-12. (in Chinese with English abstract)

Pan F (潘峰), Tian CY (田长彦), Shao F (邵峰), Zhou W (周 伟), Chen F (陈飞) (2011) Evaluation of ecological sensitivity in Karamay, Xinjiang, Northwest China. Acta Geographica Sinica (地理学报), 66, 1497-1507. (in Chinese with English abstract)

Pan YZ, Shi PJ, Zhu WQ, Gu XH, Fan YD, Li J (2005) Measurement of ecological capital of Chinese terrestrial ecosystem based on remote sensing. Science in China: Series D, 48, 786-796.

Shi DM (史东梅), Chen ZF (陈正发), Jiang GY (蒋光毅), Jiang D (江东) (2012) Comparative study on estimation methods for soil erodibility $\mathrm{K}$ in purple hilly area. Journal of Beijing Forestry University (北京林业大学学报), 34(1), 32-38. (in Chinese with English abstract)

Su WC (苏维词), Yang HK (杨汉奎) (1994) Preliminary division of eco-environmental fragility types in Guizhou karst region. Research of Environmental Sciences (环境科学研 
究), 7, 35-41. (in Chinese with English abstract)

Tian YP (田亚平), Chang H (常吴) (2012) Bibliometric analysis of research progress on ecological vulnerability in China. Acta Geographica Sinica (地理学报), 67, 1515-1525. (in Chinese with English abstract)

Wang RH (王让会), Song YD (宋郁东), Fan ZL (攀自立), You XX (游先祥) (2001) Comprehensive assessment on environmental quality in vulnerable ecotone of Tarim River Basin. Environmental Science (环境科学), 22(2), 7-11. (in Chinese with English abstract)

Wang WZ (王万忠), Jiao JY (焦菊英) (1996) Quantitative evaluation on factors influencing soil erosion in China. Bulletin of Soil and Water Conservation (水土保持通报), 16, 1-20. (in Chinese with English abstract)

Wang XD (王小丹), Zhong XH (钟祥浩), Fan JR (范建容) (2004) Assessment and spatial distribution of sensitivity of soil erosion in Tibet. Acta Geographica Sinica (地理学报), 59, 181-188. (in Chinese with English abstract)

Williams JR, Renard KG, Dyke PT (1983) EPIC: a new method for assessing erosion's effect on soil productivity.
Journal of Soil and Water Conservation, 38, 381-383.

Xiao RB (肖荣波), Ouyang ZY (欧阳志云), Wang XK (王效 科), Zhao TQ (赵同谦) (2005) Sensitivity of rocky desertification and its spatial distribution in southwestern China. Chinese Journal of Ecology (生态学杂志), 24, 551-554. (in Chinese with English abstract)

Yu BH (于伯华), Lü CH (吕昌河) (2011) Assessment of ecological vulnerability on the Tibetan Plateau. Geographical Research (地理研究), 30, 2289-2295. (in Chinese with English abstract)

Zhang DF (张殿发), Wang SJ (王世杰), Li RL (李瑞玲), Zhou DQ (周德全) (2002) Eco-geo-environment of rocky desertification and its driving mechanism-a typical example in Karst mountainous areas of Guizhou Province. Rural Eco-Environment (农村生态环境), 18(1), 6-10. (in Chinese with English abstract)

Zhao YL (赵跃龙), Liu YH (刘燕华) (1994) The division of type and decision of range on fragile environment in China. Yunnan Geographic Environment Research (云南地理环境 研究), 6(2), 34-44. (in Chinese with English abstract)

(责任编委: 薛达元 责任编辑: 黄祥忠) 